\title{
Cholate Clearance Test
}

National Cancer Institute

\section{Source}

National Cancer Institute. Cholate Clearance Test. NCI Thesaurus. Code C162162.

A test of liver function that measures the clearance of orally-administered cholate to provide an assessment of portal blood flow and IV-administered cholate to provide an assessment of systemic blood flow. 